\title{
Vanadate Treatment Restores the Expression of Genes for Key Enzymes in the Glucose and Ketone Bodies Metabolism in the Liver of Diabetic Rats
}

\author{
Alfons Valera, Joan Enric Rodriguez-Gil, and Fatima Bosch \\ Department of Biochemistry and Molecular Biology, School of Veterinary Medicine, \\ Autonomous University of Barcelona, 08193-Bellaterra, Barcelona, Spain
}

\begin{abstract}
Oral administration of vanadate to diabetic streptozotocintreated rats decreased the high blood glucose and D-3-hydroxybutyrate levels related to diabetes. The increase in the expression of the $P$-enolpyruvate carboxykinase (PEPCK) gene, the main regulatory enzyme of gluconeogenesis, was counteracted in the liver and the kidney after vanadate administration to diabetic rats. Vanadate also counteracted the induction in tyrosine aminotransferase gene expression due to diabetes and was able to increase the expression of the glucokinase gene to levels even higher than those found in healthy animals. Similarly, an induction in pyruvate kinase mRNA transcripts was observed in diabetic vanadate-treated rats. These effects were correlated with changes on glucokinase and pyruvate kinase activities. Vanadate treatment caused a decrease in the expression of the liver-specific glucose transporter, GLUT-2. Thus, vanadate was able to restore liver glucose utilization and block glucose production in diabetic rats. The increase in the expression of the mitochondrial 3-hydroxy-3-methylglutaryl-CoA synthase (HMGCoAS) gene, the key regulatory enzyme in the ketone bodies production pathway, observed in diabetic rats was also blocked by vanadate. Furthermore, a similar pattern in the expression of PEPCK, GLUT-2, HMGCoAS, and the transcription factor CCAAT / enhancer-binding protein $\alpha$ genes has been observed. All of these results suggest that the regulation of the expression of genes involved in the glucose and ketone bodies metabolism could be a key step in the normalization process induced by vanadate administration to diabetic rats. (J. Clin. Invest. 1993. 92:4-11.) Key words: $P$-enolpyruvate carboxykinase • glucokinase • pyruvate kinase • GLUT-2 • CCAAT/enhancer-binding protein $\alpha$
\end{abstract}

\section{Introduction}

The main alterations related to the diabetic process are hyperglycemia and ketoacidosis. The increase in blood glucose is mainly the result of the impairment of either liver or peripheral tissues to metabolize glucose and the activation of gluconeogenesis in the liver and the kidney (1). Hepatocytes are able to respond to fluctuations in blood glucose levels by parallel changes in the rate of glucose phosphorylation. The key en-

Address correspondence to Fatima Bosch, Department of Biochemistry and Molecular Biology, School of Veterinary Medicine, Autonomous University of Barcelona, 08193-Bellaterra, Barcelona, Spain.

Received for publication 22 June 1992 and in revised form 23 December 1992

J. Clin. Invest.

(C) The American Society for Clinical Investigation, Inc.

0021-9738/93/07/0004/08 \$2.00

Volume 92, July 1993, 4-11 zyme in the regulation of this process is glucokinase. The regulation of glucokinase activity has been strongly correlated with corresponding changes of mRNA and with rates of transcription of the glucokinase gene (2-6). In diabetic animals, where glycolysis is inoperative and gluconeogenesis is increased, glucokinase mRNA is very low $(3,5-10)$. Treatment of diabetic rats with insulin induces glucokinase gene transcription (8). Another key step in liver glucose metabolism is pyruvate kinase, which plays a central role in the regulation of the glycolytic pathway (11). These controls include short-term regulation, such as inactivation of the L-type enzyme by phosphorylation (12-14), and long-term regulation by changes in the amount of the enzyme. The alterations in the amount of this enzyme are primarily due to changes in the level of transcription of its gene $(15,16)$. Thus, mRNA concentrations, which are decreased in starvation and diabetes, are restored to normal by refeeding the animals a high carbohydrate diet and insulin administration $(17,18)$.

The cytosolic form of $P$-enolpyruvate carboxykinase $(\mathrm{PEPCK})^{1}$ is the main regulatory enzyme of gluconeogenesis (19). PEPCK has no known allosteric modifiers and responds to changes in metabolic flux over the gluconeogenic pathway by a rapid increase in enzyme protein (19). PEPCK activity is regulated by different agents through the modification of the synthesis rate of the enzyme (19). During the diabetic process, the expression of the liver PEPCK gene is markedly increased by the lack of insulin and the rise of glucagon levels (20-22). Insulin administration to streptozotocin-induced diabetic rats results in a decrease of liver PEPCK mRNA levels to those levels found in normal animals. The insulin effect (23-25) is mainly due to an inhibition of PEPCK gene transcription. On the other hand, insulin has no effect on kidney PEPCK mRNA levels, which are mainly controlled by the body acid-base status. The production of $\beta$-hydroxybutyrate and acetoacetate in diabetic acidosis results in an induction of kidney PEPCK mRNA concentration $(26,27)$. Liver ketogenesis supplies metabolic fuels for energy to peripheral tissues. Mitochondrial 3hydroxy-3-methylglutaryl-CoA synthase (HMGCoAS) is the key enzyme in the regulation of ketone bodies synthesis (2830 ). The gene for HMGCoAS has been cloned ( 31 ); its expression is rapidly changed in response to AMP, insulin, dexamethasone, and refeeding and is greatly increased by starvation and diabetes (32).

Several reports have shown that vanadate acts as an insulinlike effector in vivo by normalizing blood glucose levels in diabetic animals (33-36) and by preventing the decline in cardiac performance due to this pathological process (33). Vanadate is

1. Abbreviations used in this paper: $\mathrm{C} / \mathrm{EBP} \alpha, \mathrm{CCAAT} / \mathrm{enhancer-bind-}$ ing protein $\alpha$; HMGCoAS, 3-hydroxy-3-methylglutaryl-CoA synthase; PEPCK, $P$-enolpyruvate carboxykinase; SALT, serum alanine aminotransferase; TAT, tyrosine aminotransferase. 
also able to modify carbohydrate metabolism in both the intact animal $(34,37)$ and in isolated cells (38-43) and tissues (44). Furthermore, vanadate has been found to be a powerful inhibitor of PEPCK and tyrosine aminotransferase (TAT) gene expression in hepatoma cells (45). However, vanadate induces the expression of L-pyruvate kinase and glucokinase genes in hepatocytes in primary culture (46). The 5 ' flanking region of the PEPCK gene contains regulatory elements that are responsive to cAMP (47-52), glucocorticoids (48-50), insulin (24, 53 ), and vanadate (45). No insulin or vanadate regulatory elements have been described in glucokinase and pyruvate kinase promoters. It has been suggested that CCAAT/enhancerbinding protein $\alpha(\mathrm{C} / \mathrm{EBP} \alpha)$, a transcription factor that is highly expressed in liver and adipose tissue, could have a physiological function regulating the transcription of genes coding for enzymes of energy metabolism (54). The promoters of genes involved in this metabolism have been found to be transactivated by $\mathrm{C} / \mathrm{EBP} \alpha$ in vitro $(52,54,55)$.

The aim of this work is to analyze the effects of oral treatment of diabetic rats with vanadate in the expression of the genes for regulatory enzymes involved in liver glucose and ketone bodies metabolism. We have found that vanadate, like insulin, restores liver performance. Furthermore, since the mechanism(s) by which vanadate provokes these effects are unknown, we have investigated the effects of diabetes and vanadate treatment on the expression of $\mathrm{C} / \operatorname{EBP} \alpha$.

\section{Methods}

Materials. The random primed DNA-labeling kit was obtained from Boehringer Mannheim Biochemicals (Indianapolis, IN). $\left[{ }^{32} \mathrm{P}\right] \mathrm{dCTP}$ $(3,000 \mathrm{Ci} / \mathrm{mmol})$ was purchased from Amersham Corp. (Arlington Heights, IL). Gene Screen Plus was purchased from DuPont-New England Nuclear (Boston, MA). Sodium orthovanadate was obtained from Sigma Chemical Co. (St. Louis, MO). The other reagents used in this study were of the highest purity available. $P$-enolpyruvate carboxykinase cDNA was provided by Dr. R. W. Hanson (Case Western Reserve University, Cleveland, $\mathrm{OH}$ ), and HMGCoAS cDNA by Dr. F. G. Hegardt (University of Barcelona, Barcelona, Spain). Glucokinase cDNA was provided by Dr. P. B. Iynedjian (University of Geneva, Geneva, Switzerland). Tyrosine aminotransferase cDNA was a gift from Dr. Günter Schutz (Institut für Zell und Tumorbiologie, Heidelberg, Germany). Pyruvate kinase cDNA was a gift from Dr. A. Kahn (Institut Cochin de Genetique Moleculaire, Paris, France). Liver-specific glucose transporter (GLUT-2) cDNA was provided by Dr. G. Bell (University of Chicago, Chicago, IL). C/EBP $\alpha$ cDNA was provided by S. L. McKnight (Carnegie Institution of Washington, Baltimore, MD).

Treatment of animals. Male Sprague-Dawley rats $(180-230 \mathrm{~g})$ were used. Diabetic animals were obtained by applying a single intravenous injection of streptozotocin $(60 \mathrm{mg} / \mathrm{kg}$ body wt $)$, dissolved in a $10 \mathrm{mM}$ sodium citrate solution with $0.9 \% \mathrm{NaCl}, \mathrm{pH} 4.5$, immediately before administration. Diabetic rats were used $7 \mathrm{~d}$ after streptozocin treatment. Each diabetic state was assessed by measuring glucosuric and ketonuric levels (Gluketur Test; Ames). The animals were divided into three groups: control, diabetic, and vanadate-treated diabetic. Each group consisted of five rats. The controls and diabetic rats drank a $0.5-\mathrm{g} / 100 \mathrm{ml} \mathrm{NaCl}$ solution. The vanadate-treated animals drank a $0.5-\mathrm{g} / 100 \mathrm{ml} \mathrm{NaCl}$ solution containing freshly prepared sodium orthovanadate $(0.7 \mathrm{mg} / \mathrm{ml}) .15 \mathrm{~d}$ after treatment the animals were killed, blood was collected, and livers and kidneys were removed and quickly frozen in liquid $\mathrm{N}_{2}$. This protocol was repeated three times. Finally, a second series of experiments was performed in which the animals were divided into four groups, each one consisting of five animals: control, vanadate-treated control, diabetic, and vanadate-treated diabetic. This procedure was repeated twice and the protocol followed was as described above.

Enzyme and metabolite assays. Glucose was measured by the hexokinase method (GlucoQuant system; Boehringer Mannheim Biochemicals). D-3-hydroxybutyrate was determined by the D-3-hydroxybutyrate dehydrogenase technique (Boehringer Mannheim Biochemicals). Serum alanine aminotransferase (SALT) activity was assayed enzymatically (Boehringer Mannheim Biochemicals). Serum insulin concentration was quantified by radioimmunoassay (system INSIK-5; Soren Biomedica, Saluggia (Vercelli), Italy). To determine pyruvate kinase activities, the liver was homogenized in an ice-cold buffer containing $100 \mathrm{mM}$ potassium fluoride, $15 \mathrm{mM}$ EGTA, and $50 \mathrm{mM}$ glycilglycine, $\mathrm{pH}$ 7.4. To measure glucokinase activity, liver samples were homoge-

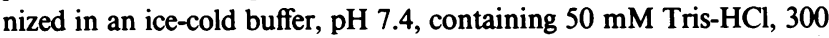
$\mathrm{mM}$ sucrose, $100 \mathrm{mM} \mathrm{KCl}, 1 \mathrm{mM}$ EDTA, and $0.7 \mu \mathrm{l} / \mathrm{ml} \beta$-mercaptoethanol. These activities were analyzed in $12,000 \mathrm{~g}$ as described in references 56 and 57 , respectively. Pyruvate kinase activity was determined at $0.15 \mathrm{mM} P$-enolpyruvate (active form) and at $5 \mathrm{mM} P$-enolpyruvate (total activity) (56). Glucokinase activity was calculated as the difference between the glucose phosphorylation capacity at 100 and $0.5 \mathrm{mM}$ glucose (57).

Northern analysis. Total RNA was extracted from tissues by the guanidine isothiocyanate method (58), and the RNA samples $(20 \mu \mathrm{g})$ were subjected to electrophoresis on $1 \%$ agarose gel containing $2.2 \mathrm{M}$ formaldehyde. Northern blots were hybridized to ${ }^{32} \mathrm{P}$-labeled cDNAs. The PEPCK cDNA probe corresponded to a 1.1-kb PstI-PstI fragment from the $3^{\prime}$ end of the PEPCK cDNA; TAT cDNA corresponded to a 600-b PstI-PstI fragment that included the $3^{\prime}$ end of the TAT cDNA; HMGCoAS, a 1,500-bp EcoRI-EcoRI fragment from the cDNA; glukokinase cDNA, a 2.3-kb EcoRI-EcoRI fragment containing the fulllength cDNA; pyruvate kinase cDNA, a 1.6-kb Pstl-Pstl fragment from the cDNA; GLUT-2 cDNA, a 1.5-kb EcoRI-EcoRI fragment from the cDNA; C/EBP $\alpha$ cDNA, a 1.9-kb BamHI-HindIII fragment from the cDNA. The $\beta$-actin probe corresponded to a 1.3-kb EcoRI-EcoRI fragment of $\beta$-actin cDNA. These probes were labeled using $\left[\alpha-{ }^{32} \mathrm{P}\right] \mathrm{dCTP}$, by following the method of random oligopriming as described by the manufacturer. The specific activity of the DNA probe labeled in this manner was $\sim 10^{9} \mathrm{cpm} / \mu \mathrm{g}$ DNA. Hybridization and washing conditions have been described previously (45). The membranes were exposed to Kodak XAR-5 film, and densitometric analysis of autoradiograms was performed at nonsaturating exposures with a scanning densitometer. The actin signal was used to correct for loading inequalities as an internal standard.

Presentation of the data and statistical analysis. Any variability attributable to the experimental procedures was ruled out because in studies of individual RNA samples the correlation coefficient between increasing amounts of input RNA and signal intensity was 0.99 for all transcripts. To analyze the effects of perturbations independently of variability in basal gene expression, the densitometric readings of experimental samples were expressed as a percentage of readings in paired samples of nontreated control rats (always tested in the same Northern blot) after correction for loading differences with the actin signal. The data were summarized with the mean \pm SEM. Statistical analysis was carried out by analysis of variance followed by the Newman-Keuls test for multiple comparisons (59). Differences were considered statistically significant at $P<0.05$.

\section{Results}

Effects of vanadate on serum parameters. In agreement with previous reports (33-36), a 15-d treatment of streptozotocin diabetic rats with vanadate decreased the blood glucose levels, which had been augmented in the diabetic state (Table I). This glucose normalization was a result of vanadate action since no increase in blood insulin was detected in diabetic vanadatetreated animals ( Table I). In addition, vanadate restored body weight and fluid intake of diabetic animals (Table I). Further- 
Table I. Effects of Vanadate Treatment on Body Weight, Fluid Intake, and Serum Parameters

\begin{tabular}{|c|c|c|c|c|c|c|}
\hline Group & $\begin{array}{l}\text { Weight } \\
\text { gain }\end{array}$ & $\begin{array}{c}\text { Fluid } \\
\text { intake }\end{array}$ & $\begin{array}{l}\text { Blood } \\
\text { glucose }\end{array}$ & SALT & $\begin{array}{l}\beta \text {-Hydroxy- } \\
\text { butyrate }\end{array}$ & Insulin \\
\hline & $g$ & $m l / d$ & $m g / d l$ & U/liter & $m M$ & $n g / m l$ \\
\hline \multicolumn{7}{|l|}{ Control } \\
\hline Nontreated $(n=25)$ & $53 \pm 9$ & $46 \pm 6$ & $136 \pm 10$ & $49 \pm 1$ & $0.10 \pm 0.03$ & $20.5 \pm 1.8$ \\
\hline Vanadate treated $(n=10)$ & $38 \pm 9^{*}$ & $30 \pm 9^{*}$ & $130 \pm 11$ & $48 \pm 2$ & $0.13 \pm 0.05$ & $18.3 \pm 2.0$ \\
\hline \multicolumn{7}{|l|}{ STZ-diabetic } \\
\hline Nontreated $(n=25)$ & $2 \pm 3^{8}$ & $290 \pm 18^{\S}$ & $501 \pm 25^{\S}$ & $105 \pm 10^{\S}$ & $1.48 \pm 0.35^{\S}$ & $6.9 \pm 1.6^{5}$ \\
\hline Vanadate treated $(n=25)$ & $13 \pm 5^{\ddagger}$ & $35 \pm 10$ & $195 \pm 17^{*}$ & $52 \pm 5$ & $0.36 \pm 0.16^{*}$ & $6.1 \pm 1.5^{8}$ \\
\hline
\end{tabular}

Glucose, SALT, D-3-hydroxybutyrate, and insulin were measured as described in Methods. Results are expressed as means \pm SEM for the number of animals in parentheses and the significance of differences was tested by Student's $t$ test: ${ }^{*} P<0.05,{ }^{\ddagger} P<0.01,{ }^{\S} P<0.001$ vs. nontreated controls.

more, vanadate induced a strong reduction $(\sim 75 \%)$ in the increased levels of $\mathrm{D}$-3-hydroxybutyrate caused by diabetes ( $\mathrm{Ta}$ ble I). These results agreed with a normalization in the metabolic state in the diabetic animals after treatment.

We also measured SALT activity, since it is one of the most commonly used parameters to detect hepatic damage. As shown in Table I, streptozotocin treatment induced a significant increase in this enzymatic activity in serum. Vanadate administration to these animals resulted in a decrease of SALT activity to the levels of healthy animals, suggesting that this compound was able to restore the liver tissue to normal status in diabetic rats.

Effects of vanadate on glucokinase and pyruvate kinase gene expression and enzyme activity in normal and diabetic rats. Since vanadate was able to normalize blood glucose levels when administered to diabetic rats, a possible mechanism to explain this action might involve an induction in glucokinase gene expression. Total RNA was isolated from the liver of normal and diabetic animals and analyzed by Northern blotting. Although no significant differences were detected in vanadatetreated control animals ( $96 \pm 15 \%$ of nontreated controls), oral treatment of diabetic rats with vanadate caused an induction of liver glucokinase mRNA concentrations, which increased from $10 \pm 5 \%$ in nontreated diabetic rats to $255 \pm 72 \%$ in vanadatetreated diabetic rats $(P<0.01)$, related to control nontreated animals (Fig. $1 A$ ). A similar pattern was observed when glucokinase activity was determined in the liver of the animals. As shown in Table II, oral treatment with vanadate of control rats did not cause any significant modification of glucokinase activity compared with control nontreated animals. The glucokinase activity of diabetic rats was very low, but a great increase in the enzyme activity was noted in diabetic rats treated with van-
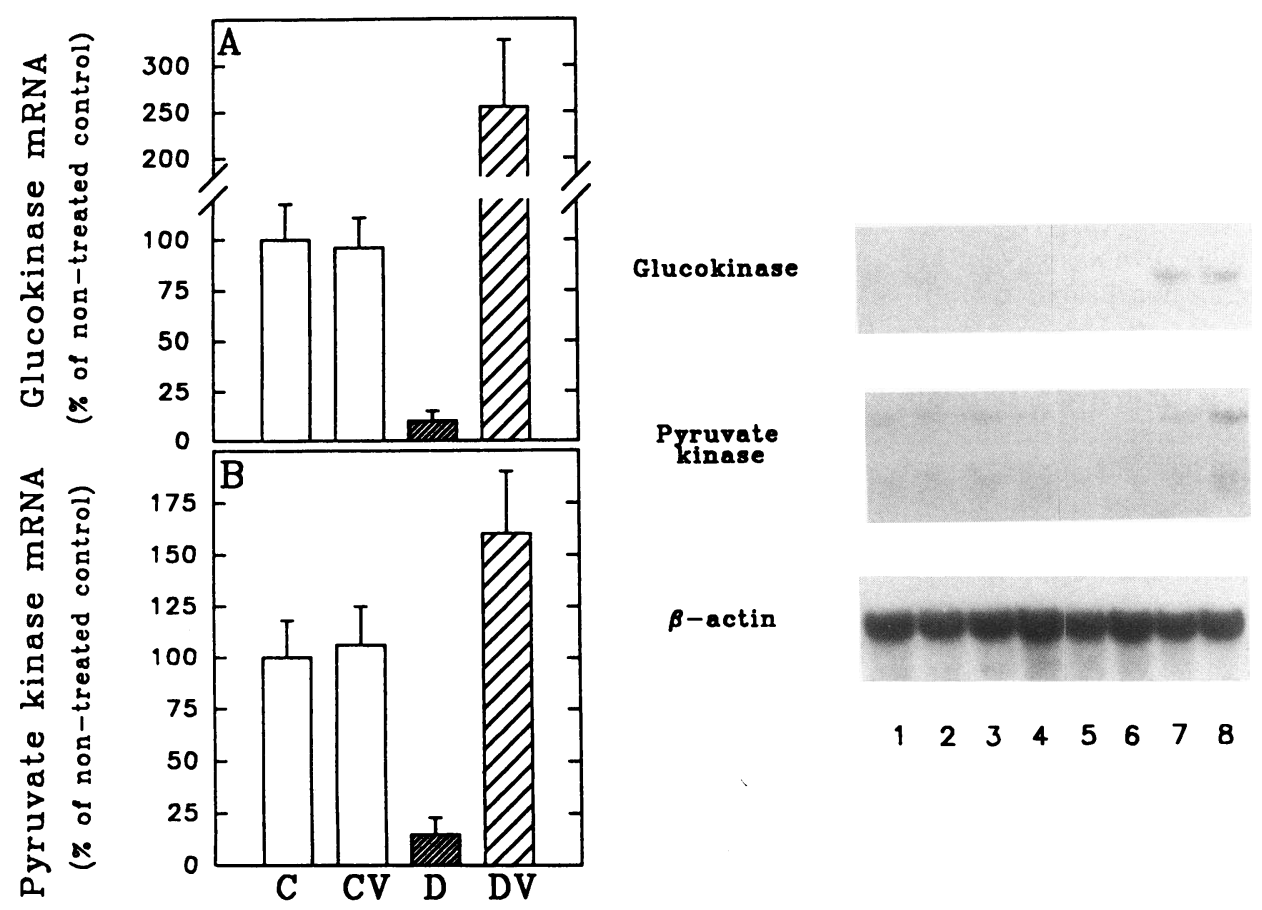

$\begin{array}{llllllll}1 & 2 & 3 & 4 & 5 & 6 & 7 & 8\end{array}$
Figure 1. Effects of vanadate treatment on glucokinase and pyruvate kinase mRNA concentrations. (Left): The concentrations of mRNA for glucokinase $(A)$ and pyruvate kinase (3.2-kb transcript) $(B)$ were determined by Northern analysis of total RNA ( $20 \mu \mathrm{g}$ per sample) isolated from the liver of nontreated control rats $(C)(n$ $=25)$, control rats treated with vanadate $(C V)(n=10)$, nontreated diabetic rats $(D)(n=25)$, and diabetic rats treated with vanadate $(D V)(n=25)$ as described in Methods. Signal intensity was quantified by densitometry and the readings obtained were expressed as a percentage of readings in paired nontreated control animals after correction for loading inequalities with the $\beta$-actin signal. Each bar represents the mean \pm SEM. (Right): Northern blots from two representative animals of each group $(\mathrm{C}$, lanes 1 and 2 ; CV, lanes 3 and 4; D, lanes 5 and $6 ; \mathrm{DV}$, lanes 7 and 8 ) are shown. 
adate (Table II). This increase was even higher than that observed in control animals $(\sim 60 \%)$.

An increase of glucose utilization through hepatic glycolysis could also contribute in decreasing hyperglycemia. When Ltype pyruvate kinase gene expression was determined, very low concentrations of pyruvate kinase mRNA ( $15 \pm 8 \%$ of the nontreated control) were detected in diabetic livers. However, a $160 \pm 30 \%$ induction in the three pyruvate kinase mRNA transcripts of 3.2-, 2.2-, and 2.0-kb was observed after vanadate treatment of diabetic rats (Fig. $1 B$ ). No significant changes were observed in the concentration of pyruvate kinase mRNA in control animals treated with vanadate compared with control nontreated rats $(106 \pm 19 \%)$. The changes in pyruvate kinase activity showed a pattern similar to that detected in mRNA concentrations. Both pyruvate kinase activities at low (active form) and high (total activity) concentrations of the substrate were not modified by vanadate treatment of control animals, whereas the effector was able to counteract the inhibition of the enzyme caused by diabetes (Table II).

Effects of vanadate on PEPCK and TAT gene expression in normal and diabetic rats. To decrease blood glucose levels, in addition to stimulating glucose use, vanadate may decrease glucose production through gluconeogenesis. In this regard, we studied the effects of vanadate treatment on the expression of the PEPCK gene in the liver and kidney of healthy and diabetic animals, since the activity of PEPCK is regulated at the level of the transcription of its gene. Fig. 2 shows that diabetes caused an increase of $660 \pm 118 \%$, related to control rats, in the expression of the liver PEPCK gene. The administration of vanadate produced a significant reduction of these mRNA concentrations up to $240 \pm 80 \%$ of the control animals. However, no significant modification was observed on PEPCK mRNA concentrations in the liver of control rats treated with vanadate (data not shown). In addition, we also detected a $550 \pm 100 \%$ increase in the kidney PEPCK mRNA concentrations in diabetic rats compared with control animals and a reduction to $220 \pm 35 \%$ after treatment with vanadate (Fig. 3). These results show that the administration of vanadate to diabetic animals was able to affect the expression of the PEPCK gene in different tissues.

Table II. Effects of Vanadate Treatment on Liver Glucokinase and Pyruvate Kinase Activities

\begin{tabular}{llll}
\hline & & \multicolumn{2}{c}{ Pyruvate kinase } \\
\cline { 3 - 4 } \multicolumn{1}{c}{ Group } & Glucokinase & Active & Total \\
\hline & & U/g liver & \\
Control & & & \\
$\quad$ Nontreated $(n=12)$ & $3.1 \pm 0.7$ & $23.5 \pm 1.9$ & $46.8 \pm 4.1$ \\
$\quad$ Vanadate treated $(n=10)$ & $2.9 \pm 0.8$ & $25.1 \pm 2.0$ & $48.3 \pm 4.8$ \\
STZ-diabetic & & & \\
$\quad$ Nontreated $(n=25)$ & $0.1 \pm 0.1^{\S}$ & $1.9 \pm 0.2^{\S}$ & $12.1 \pm 1.7^{\S}$ \\
$\quad$ Vanadate treated $(n=10)$ & $5.2 \pm 0.9^{*}$ & $34.7 \pm 2.3^{\ddagger}$ & $65.5 \pm 4.5^{\ddagger}$ \\
& & & \\
\hline
\end{tabular}

Glucokinase and piruvate kinase activities were determined as indicated in Methods. Results are expressed as means \pm SEM for the number of animals in parentheses and the significance of differences was tested by Student's $t$ test: ${ }^{*} P<0.05,{ }^{\ddagger} P<0.01,{ }^{\S} P<0.001$ vs. nontreated controls.

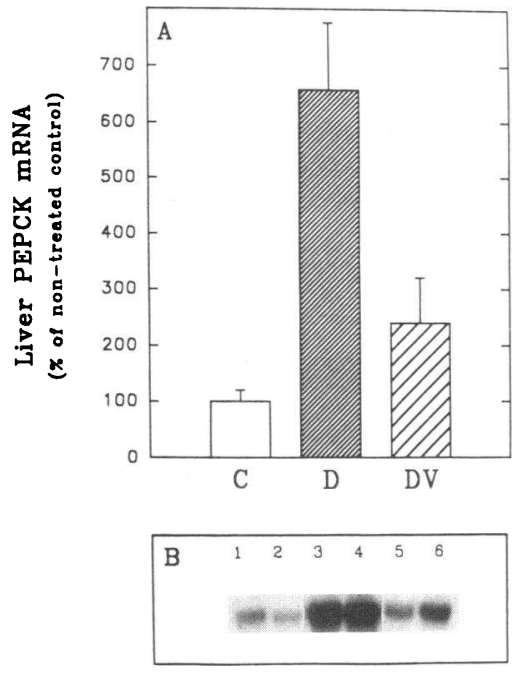

Figure 2. Effects of vanadate treatment on liver PEPCK mRNA concentrations. $(A)$ The concentration of mRNA for PEPCK was determined by Northern analysis of total RNA isolated from the liver of control rats $(C)$, diabetic rats $(D)$, and diabetic rats treated with vanadate $(D V)$. Each experimental group consisted of 15 animals. The data are expressed as a percentage of the nontreated control animals. Results represent the mean

\pm SEM. $(B)$ Northern blots from two representative animals of each group (C, lanes 1 and $2 ; \mathrm{D}$, lanes 3 and 4 ; DV, lanes 5 and 6 ) are shown.

We also investigated the effects of vanadate on TAT, another enzyme related to gluconeogenesis and regulated at the level of gene expression in a similar manner as PEPCK (60$62)$. cAMP and glucocorticoids induce the expression of the gene whereas insulin inhibits TAT gene expression $(63,64)$. In this study a similar pattern of modification $(480 \pm 70 \%$ induction caused by diabetes and reduction to $180 \pm 38 \%$ after vanadate treatment) of the expression of the gene for TAT was detected (Fig. 4).

Effects of vanadate on liver glucose-transporter GLUT-2 gene expression. GLUT-2, the liver- and pancreas-specific glucose transporter, is involved in glucose uptake and release processes $(65)$. Insulin treatment of diabetic animals decreases the amount of protein and mRNA of GLUT-2 (66). However, little is known about the regulation of the expression of this glucose transporter in the liver. We analyzed the effects of diabetes and vanadate administration on the expression of this glucose transporter. Fig. 5 shows that although diabetes caused

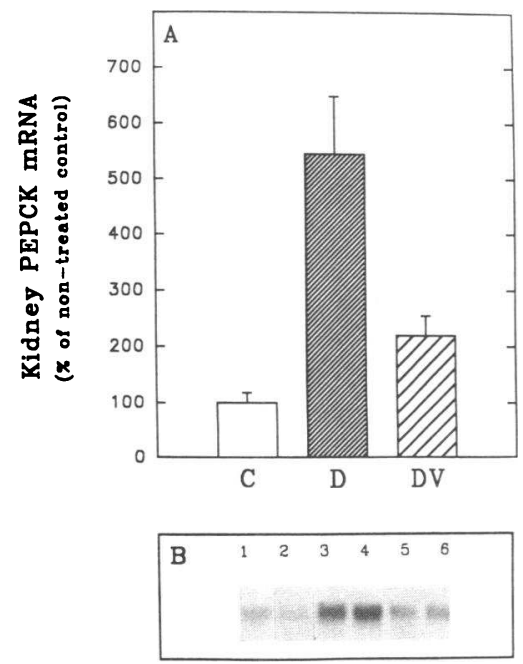

Figure 3. Effects of vanadate treatment on kidney PEPCK mRNA concentrations. $(A)$ The concentration of mRNA for PEPCK was determined by Northern analysis of total RNA isolated from the kidney of control rats $(C)$, diabetic rats $(D)$, and diabetic rats treated with vanadate $(D V)$. Each experimental group consisted of 15 animals. The data are expressed as a percentage of the nontreated control animals and results are mean \pm SEM.

(B) Northern blots from two representative animals of each group are shown as described in Fig. 2. 

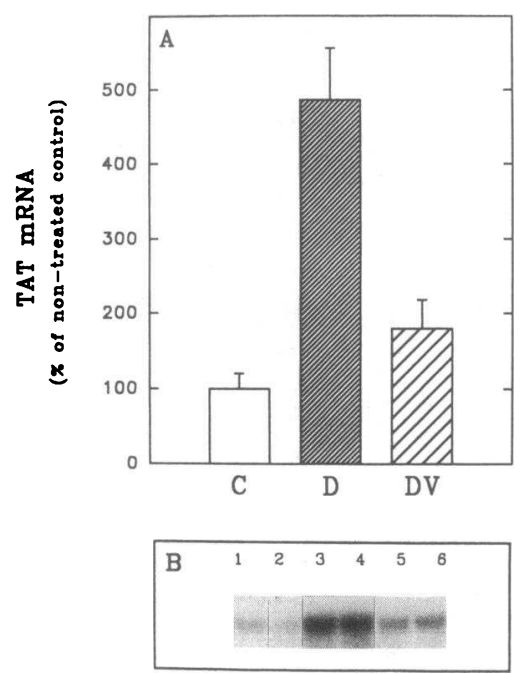

Northern blots from two representative animals of each group $(\mathrm{C}$, lanes 1 and 2; D, lanes 3 and $4 ; \mathrm{DV}$, lanes 5 and 6 ) are shown.

a $220 \pm 45 \%$ induction in GLUT-2 gene expression, vanadate treatment of diabetic rats reduced the mRNA concentrations to those detected in the liver of healthy animals $(85 \pm 18 \%)$. No changes of the GLUT-2 mRNA concentrations were noted in control animals treated with vanadate compared with control nontreated animals (data not shown).

Effects of vanadate on mitochondrial HMGCOAS gene expression. As already described in Table I, vanadate treatment provoked a $75 \%$ reduction in the increased levels of D-3-hydroxybutyrate caused by diabetes. Thus, we next investigated the effect of vanadate treatment on the expression of the mitochondrial HMGCoAS gene. Fig. 6 shows that although diabetes produced an increase $(270 \pm 52 \%$ over the control nontreated rats) in specific HMGCoAS mRNA concentrations, vanadate administration to diabetic rats caused a decrease of these concentrations (to $120 \pm 28 \%$ of nontreated control animals), which resulted in a normalization of the expression of the gene in these animals.

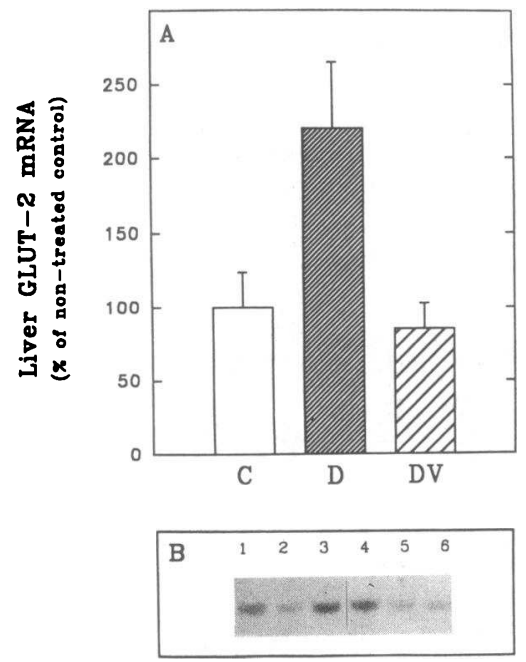

Figure 5. Effects of vanadate treatment on liver GLUT-2 mRNA concentrations. $(A)$ The concentration of mRNA for GLUT-2 was determined by Northern analysis of total RNA isolated from the liver of control rats $(C)$, diabetic rats $(D)$, and diabetic rats treated with vanadate $(D V)$. Each experimental group consisted of 15 animals. The data are expressed as a percentage of the nontreated control animals and results are mean \pm SEM.

$(B)$ Northern blots from two representative animals of each group (C, lanes 1 and 2; D, lanes 3 and 4; DV, lanes 5 and 6 ) are shown.
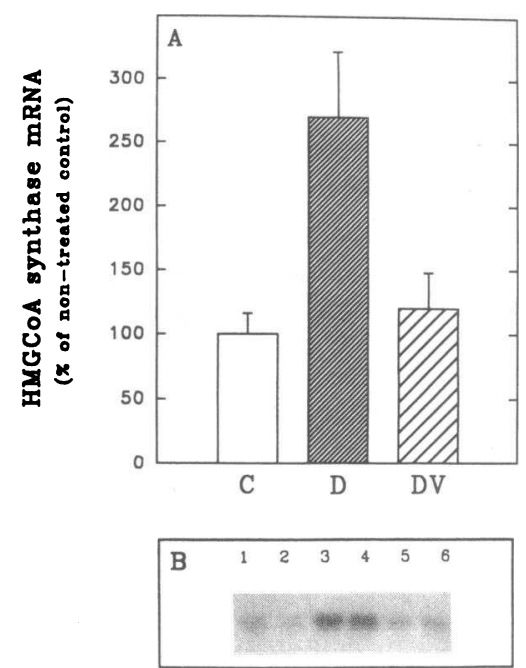

Figure 6. Effects of vanadate treatment on liver mitochondrial HMGCoAS mRNA concentrations. $(A)$ The concentration of mRNA for HMGCoAS was determined by Northern analysis of total RNA isolated from the liver of control rats $(C)$, diabetic rats $(D)$, and diabetic rats treated with vanadate $(D V)$. Each experimental group consisted of 15 animals. The data are expressed as a percentage of the nontreated control animals and results are mean \pm SEM. $(B)$ Northern blots from two representative animals of each group are presented as described in the Fig. 2 legend.

Effects of vanadate administration to the $C / E B P \alpha$ gene expression. To investigate a role of C/EBP $\alpha$ in the regulation of the expression of the genes involved in key steps in the regulation of carbohydrate and ketone bodies metabolism, we further analyzed the expression of this gene in the liver of diabetic and diabetic vanadate-treated rats. Fig. 7 shows that although vanadate treatment did not produce any significant effect on $\mathrm{C} /$ EBP $\alpha$ mRNA concentrations in control rats, diabetes caused an induction in the expression of liver C/EBP $\alpha(142 \pm 28 \%$ of nontreated control animals). However, when the animals were treated with vanadate, a decrease of C/EBP $\alpha$ mRNA concentrations was detected compared with diabetic rats. The concentration of C/EBP $\alpha$ mRNA reached in diabetic treated animals was lower than in control nontreated animals $(70 \pm 14 \%)$.

\section{Discussion}

In this study, we have investigated the role of vanadate in restoring the normal metabolic state in diabetic animals. In the last few years, many reports have been available regarding the insulin-like actions of vanadate in regulating glucose metabolism either in vivo (33-37) or in vitro (38-44). Our results indicate

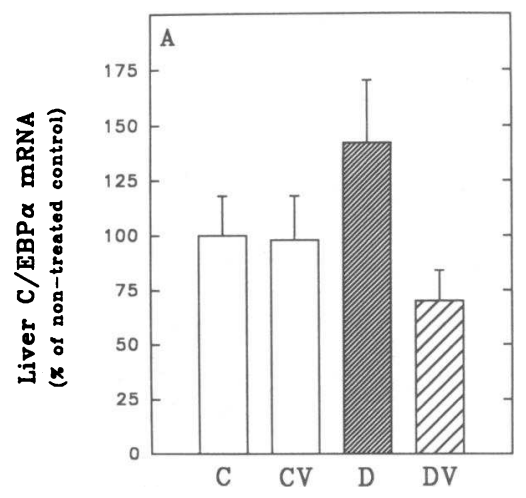

Figure 7. Effects of vanadate treatment on liver $\mathrm{C} / \mathrm{EBP} \alpha$ transcription factor mRNA levels. The level of mRNA for $\mathrm{C} / \mathrm{EBP} \alpha$ was determined by Northern analysis of total RNA isolated from the liver of control rats $(C)(n$ $=25)$, control rats treated with vanadate $(C V)(n=10)$, diabetic rats $(D)(n=25)$, and diabetic rats treated with vanadate $(D V)(n=25)$. The data are expressed as a percentage of nontreated control animals and results are mean \pm SEM. 


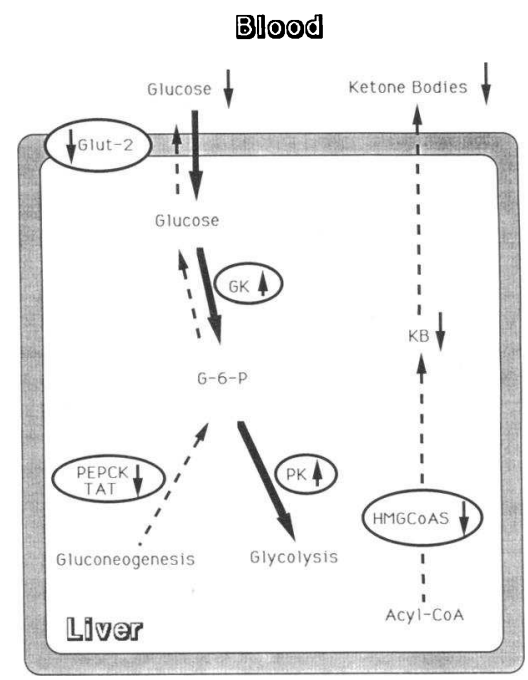

Figure 8. Schematic representation of the pathways of hepatic glucose and ketone bodies metabolism. The dark arrows indicate the pathways activated by vanadate. The brokenline arrows depict the pathways inhibited by vanadate. $K B$, ketone bodies; $G K$, glucokinase; $P K$, pyruvate kinase; $H M G C O A S$, HMGCoA synthase.

that vanadate is also able to normalize blood ketone bodies levels, which results in a decrease of the acidosis state in the diabetic animal. In addition, SALT activity was normalized after vanadate treatment. Presumably, an initial increase in SALT activity could be an indication of liver damage arising from the toxic effects of the streptozotocin injection. However, 3 wk after the injection of the drug, the metabolic acidosis might provoke hepatic damage, which would induce the high levels of SALT activity that we have detected in diabetic rats.

These metabolic effects of vanadate could probably be the result of changes in the expression of genes coding for regulatory enzymes, as is shown in the present study. A decrease of glucose production could be due to the inhibition of PEPCK gene expression. Vanadate decreased PEPCK mRNA levels in livers of diabetic rats, whereas it did not provoke any specific effect in normal animals (data not shown). Vanadate counteracted the effects mediated by cAMP in the liver, probably acting through regulatory elements on the PEPCK promoter that respond to CAMP. We have previously shown sequences responsive to vanadate between -109 and -68 on the 5 ' flanking region of the PEPCK gene (45). The most likely target for vanadate in that region is cAMP regulatory element-1, which maps from -91 to $-84(51)$. This indicates a major difference in the site of action of vanadate and insulin, since an insulin-responsive element has been located between -416 and -407 on the PEPCK promoter (67). However, the synthesis of this enzyme in the rat kidney is not responsive to $\operatorname{cAMP}(26,27)$ and its mRNA abundance is not altered by cAMP or starvation (68). The injection of triamcinolone, as well as the induction of metabolic acidosis by $\mathrm{NH}_{4} \mathrm{Cl}$, caused a marked enhancement of renal PEPCK mRNA $(27,68)$. In diabetic animals we observed a fivefold induction in the expression of this gene in the kidney, probably because of the increase of blood 3-hydroxybutyrate, resulting from the activation of the HMGCoAS in the liver of diabetic rats $(69,70)$. In addition, the expression of HMGCoAS is induced during diabetes (32). Vanadate treatment decreased HMGCoAS mRNA concentrations caused by diabetes to levels observed in healthy animals. Vanadate treatment was shown to be able to counteract the increase in kidney PEPCK mRNA levels, probably as a result of either the reduction of ketone bodies levels and the normalization of the body acid-base balance and/or a direct effect on the PEPCK promoter. However, no data are available regarding the action of vanadate on the PEPCK promoter in the kidney.

In our study, the expression of the gene for TAT, an enzyme also related with gluconeogenesis, was regulated like PEPCK. TAT gene expression is restricted to parenchymal cells of the liver (71) and it is activated by glucocorticoids and glucagon (60-62). TAT expression is undetectable during gestation but increases rapidly within the first hours after birth as a result of the increase in the glucagon/insulin ratio in newborn animals (72). The increase in this ratio could be the cause of the high expression of the TAT genes in diabetes. Vanadate treatment was able to block the induction of TAT mRNA levels, suggesting that vanadate may interfere with the cAMP-mediated activation of the TAT promoter. However, no data are available regarding the effects of vanadate on specific transcription factors involved in the control of this promoter.

Like insulin, vanadate not only decreases gene expression, it is also able to induce the expression of the genes for glucokinase and pyruvate kinase in primary cultured hepatocytes (46). The results presented in this paper indicate that vanadate treatment also induces the expression of these genes in the intact animal, which is impaired by the diabetic process. However, no changes in the expression of both genes are detected in healthy rats treated with vanadate. Furthermore, vanadate treatment of diabetic rats also causes an induction in glucokinase and pyruvate kinase mRNA concentrations. This effect is also found in cultured hepatocytes, where the induction of these genes is higher in the presence of glucose (46). Blood glucose levels detected in vanadate-treated diabetic animals are 1.5-fold higher than in controls, which might be responsible for the increase in the expression of both genes. Despite several reports describing glucokinase and pyruvate kinase gene promotor regulatory regions, the mechanism by which vanadate regulates the expression of both genes is still not known and responsive elements to this effector have not yet been described. The effects of vanadate on glucokinase and pyruvate kinase mRNA concentrations are directly related with glucokinase and pyruvate kinase activities. These results are in agreement with previous reports that indicate that vanadate administration to diabetic rats restores 6-phosphofructo-2-kinase and glucokinase activities (34).

Regarding glucose transport, the liver plays a dual role in that glucose uptake occurs from circulation when gluconeogenesis and glycogenolysis are low, but it releases glucose when gluconeogenesis and glycogenolysis are activated, such as in the insulin-deficient diabetic state. Diabetic rats presented an increase in the amount of protein and mRNA for GLUT-2 (66). Insulin treatment of these animals decreased the amount of protein and mRNA toward levels observed in nondiabetic animals (66). A great efflux of glucose occurs from the liver in the absence of insulin and the glucose transporter plays an important role in this condition. However, it has recently been suggested that the increase in GLUT-2 mRNA levels observed in a diabetic liver could be attributed to high glucose concentrations rather than to insulin deficiency (73).

It has been suggested that regulation of energy balance could be channeled through the liver-enriched transcription factor $\mathrm{C} / \mathrm{EBP} \alpha$. The concentration of $\mathrm{C} / \mathrm{EBP} \alpha$ increased dramatically in the liver of the fetal rat $3 \mathrm{~d}$ before birth (74). The expression of PEPCK (75) and TAT (73) genes starts a few 
hours after birth. Moreover, $\mathrm{C}^{14 \mathrm{CoS}}$ albino-mutant mice, which lack the "hepatocyte-specific developmental regulation" ( $h s d r$ 1) locus on chromosome 7 , showed a strong reduction of transcription rates of the C/EBP $\alpha$ gene shortly before birth and failed to activate a group of hepatic enzymes perinatally ( 54 , 76). One subset of such affected genes includes PEPCK, serin dehydratase, glucose 6-phosphatase, TAT, and aldolase B, which are involved in gluconeogenesis. These mice died a few hours after birth, presumably as a consequence of hypoglycemia. C/EBP $\alpha$ has been shown to transactivate PEPCK in vitro $(54,76)$ and our results indicated that this transcription factor was induced by diabetes, suggesting that $\mathrm{C} / \mathrm{EBP} \alpha$ could affect PEPCK gene expression in vivo. Similarities were found between C/EBP $\alpha$ and PEPCK, HMGCoAS, and GLUT-2 genes regarding their pattern of expression. Vanadate may act on these subsets of genes involved in energy metabolism at least in part through the regulation of $\mathrm{C} / \mathrm{EBP} \alpha$. The observations that $\mathrm{C} / \mathrm{EBP} \alpha$ avidly binds to cAMP response element-1 (CRE-1) on the PEPCK promoter, which overlaps the sequence described to be responsive to vanadate (42), and that there is an inhibition of both $\mathrm{C} / \mathrm{EBP} \alpha$ and PEPCK gene expression in diabetic rats after vanadate administration, suggested that vanadate may act on the expression of the PEPCK gene through modifications of the $\mathrm{C} / \mathrm{EBP} \alpha$ transcription factor in vivo.

In conclusion, the increase of the glucokinase and L-pyruvate kinase mRNA concentrations and the inhibition of PEPCK gene expression may contribute to the decrease of blood glucose levels observed after oral treatment with vanadate. As summarized in Fig. 8, the induction of glucokinase will augment glucose entry into metabolic pathways. The rise of L-pyruvate kinase will allow the use of the newly synthetized glucose 6-phosphate through glycolysis. The inhibition of PEPCK will block liver glucose production, dramatically increased during diabetes, which correlates with the decrease in GLUT-2 expression. On the other hand, the inhibition of HMGCoAS gene expression will result in a decrease on ketone bodies production, which is reflected in the reduction of blood D-3-hydroxybutyrate levels. Finally, vanadate might restore the carbohydrate and ketone bodies metabolism at least in part through the regulation of specific transcription factors, including members of the C/EBP family involved in the control of energy metabolism.

\section{Acknowledgments}

We thank Carles Hug Ros and Anna Vilalta for their excellent technical assistance.

This work was supported by grants PB87-0760 from the Dirección General de Investigación Científica y Técnica, Ministry of Education, and FISss (90/302), Ministry of Health, Spain. A. Valera was a recipient of a Fellowship from the Formación de Personal Investigador (Ministry of Education, Spain).

\section{References}

1. Taylor, R., and L. Agius. 1988. The biochemistry of diabetes. Biochem. J. 250:625-640.

2. Granner, D. K., and S. Pilkis. 1990. The genes of hepatic metabolism. $J$. Biol. Chem. 265:10173-10176.

3. Sibrowski, W., and H. J. Seitz. 1984. Rapid action of insulin and cyclic AMP in the regulation of functional messenger RNA coding for glucokinase in rat liver. J. Biol. Chem. 259:343-346.
4. Spence, J. T. 1983. Levels of translatable mRNA coding for rat liver glucokinase. J. Biol. Chem. 258:9143-9146.

5. Iynedjian, P. B., C. Ulca, and B. Mach. 1987. Molecular cloning of glucokinase cDNA. Developmental and dietary regulation of glucokinase mRNA in rat liver. J. Biol. Chem. 262:6032-6038.

6. Iynedjian, P. B., A. Gjinovci, and A. E. Renold. 1988. Stimulation by insulin of glucokinase gene transcription in liver of diabetic rats. J. Biol. Chem. 263:740-744.

7. Andreone, T. L., R. L. Printz, S. J. Pilkis, M. A. Magnuson, and D. K. Granner. 1989. The amino acid sequence of rat liver glucokinase deduced from cloned cDNA. J. Biol. Chem. 264:363-369.

8. Magnuson, M. A., T. L. Andreone, R. L. Printz, S. Koch, and D. K. Granner. 1989. Rat glucokinase gene: structure and regulation by insulin. Proc. Natl. Acad. Sci. USA. 86:4838-4842.

9. Iynedjian, P. B., D. Jotterand, T. Nouspikel, M. Asfari, and P. R. Pilot. 1989. Transcriptional induction of glucokinase gene by insulin cultured liver cells and its repression by the glucagon-cAMP system. J. Biol. Chem. 264:2182421829.

10. Nishi, S., S. Seino, and G. I. Bell. 1988. Human hexokinase. Sequences of amino- and carboxy-terminal halves are homologous. Biochem. Biophys. Res. Commun. 157:937-943.

11. Pilkis, S. J., M.-R. El-Maghrabi, and T. H. Clauss. 1988. Hormonal regulation of hepatic gluconeogenesis and glycolysis. Annu. Rev. Biochem. 57:755-783.

12. Taunton, O. D., F. B. Stifel, H. L. Greene, and R. H. Herman. 1974. Rapid reciprocal changes in rat hepatic glycolytic enzymes and fructose diphosphatase activities following insulin and glucagon injection. J. Biol. Chem. 249:7228-7239.

13. Ljungström, O., G. Hjelmquist, and L. Engström. 1974. Phosphorylation of purified rat liver pyruvate kinase by cyclic 3'5'-AMP-stimulated protein kinase. Biochim. Biophys. Acta. 358:289-298.

14. Riou, J. P., T. H. Claus, and S. J. Pilkis. 1978. Stimulation by glucagon of "in vivo" phosphorylation of rat hepatic pyruvate kinase. J. Biol. Chem. 253:656-659.

15. Decaux, J. F., B. Antoine, and A. Kahn. 1989. Regulation of the expression of the L-type pyruvate kinase gene expression in adult rat hepatocytes in primary culture. J. Biol. Chem. 264:11584-11590.

16. Vaulont, S. A., A. Munnich, J. F. Decaux, and A. Kahn. 1986. Transcriptional and post-transcriptional regulation of L-type pyruvate kinase gene expression in rat liver. J. Biol. Chem. 261:7621-7625.

17. Miyonaga, O., M. Nagono, and G. L. Cottam. 1982. Effect of insulin on liver pyruvate kinase "in vivo" and "in vitro." J. Biol. Chem. 257:10617-10623.

18. Pool, G. P., A. D. Postle, and D. P. Bloxham. 1982. The induction of synthesis of L-type pyruvate kinase in cultured rat hepatocytes. Biochem. J. 204:81-87.

19. Tilghman, S. M., F. J. Ballard, and R. W. Hanson. 1976. Gluconeogenesis: Its Regulation in Mammalian Species. R. W. Hanson and M. A. Mehlman, eds. John Wiley \& Sons, Inc., New York. 47.

20. Tilghman, S. M., R. W. Hanson, L. Reshef, M. F. Hopgood, and F. J. Ballard. 1974. Rapid loss of translatable messenger RNA of phosphoenolpyruvate carboxykinase during glucose repression in liver. Proc. Nat. Acad. Sci. USA. 71:1304-1308.

21. Hopgood, M. F., F. J. Ballard, L. Reshef, and R. W. Hanson. 1973. Synthesis and degradation of phosphoenolpyruvate carboxykinase in rat liver and adipose tissue: changes during a starvation-re-feeding cycle. Biochem. J. $134: 445-453$

22. Kioussis, D., L. Reshef, H. Cohen, S. Tilghman, P. B. Iynedjian, F. J. Ballard, and R. W. Hanson. 1978. Alterations in translatable messenger RNA coding for phosphoenolpyruvate carboxykinase (GTP) in rat liver cytosol during deinduction. J. Biol. Chem. 253:4327-4332.

23. Granner, D., T. Andreone, K. Sasaki, and E. Beale. 1983. Inhibition of transcription of the phosphoenolpyruvate carboxykinase gene by insulin. Nature (Lond.). 305:549-551.

24. Magnuson, M. A., P. G. Quinn, and D. K. Granner. 1987. Multihormonal regulation of phosphoenolpyruvate carboxykinase-chloramphenicol acetyltransferase fusion genes: insulin's effects oppose those of cAMP and dexamethasone. J. Biol. Chem. 262:14917-14920.

25. Chu, D. T, W, C. M. Davis, N. B. Chrapkiewicz, and D. K. Granner. 1988. Reciprocal regulation of gene transcription by insulin: inhibition of the phosphoenolpyruvate carboxykinase gene and stimulation of gene 33 in a single cell type. J. Biol. Chem. 263:13007-13011.

26. Iynedjian, P. B., F. J. Ballard, and R. W. Hanson. 1975. Regulation of phosphoenolpyruvate carboxykinase (GTP) synthesis in rat kidney cortex. Role of acid-base balance and glucocorticoids. J. Biol. Chem. 250:5596-5603.

27. Iynedjian, P. B., and R. W. Hanson. 1977. Messenger RNA for renal phosphoenolpyruvate carboxykinase (GTP). Its translation in a heterologous cell-free system and its regulation by glucocorticoids and by changes in acid-base balance. J. Biol. Chem. 252:8398-8403.

28. Williamson, D. H., M. W. Bates, and H. A. Krebs. 1968. Activity and 
intracellular distribution of enzymes of ketone-body metabolism in rat liver. Biochem. J. 108:353-361.

29. Lowe, D. M., and P. K. Tubbs. 1985. Succynilation and inactivation of 3-hydroxy-3-methylglutaryl-CoA synthase by succinil-CoA and its possible relevance to the control of ketogenesis. Biochèm. J. 232:37-42.

30. Holness, M. J., T. J. French, P. S. Schofield, and M. C. Sugden. 1987. The relationship between fat synthesis and oxidation in the liver after re-feeding and its regulation by thyroid hormone. Biochem. J. 247:621-626.

31. Ayte, J., G. Gil-Gómez, D. Haro, P. F. Marrero, and F. G. Hegardt. 1990. Rat mytochondrial and cytosolic 3-hydroxy-3-methylglutaryl-CoA synthases are encoded by two different genes. Proc. Natl. Acad. Sci. USA. 87:3874-3878.

32. Casals, N., N. Roca, M. Guerrero, G. Gil-Gomez, J. Ayté, C. J. Ciudad, and F. G. Hegardt. 1992. Regulation of the expression of the mitochondrial 3-hydroxy-3-methylglutaryl-CoA synthase gene. Biochem. J. 283:261-264.

33. Heyliger, C., A. G. Tahiliani, and J. H. McNeill. 1985. Effect of vanadate on elevated blood glucose and depressed cardiac performance of diabetic rats. Science (Wash. DC). 277:1474-1477.

34. Gil, J., M. Miralpeix, J. Carreras, and R. Bartrons. 1988. Insulin-like effects of vanadate on glucokinase activity and fructose 2,6-bisphosphate levels in the liver of diabetic rats. J. Biol. Chem. 263:1868-1871.

35. Meyerovitch, J., Z. Farfel, J. Sack, and Y. Shechter. 1987. Oral administration of vanadate normalizes blood glucose levels in streptozotocin-treated rats. $J$. Biol. Chem. 262:6658-6662.

36. Blondel, O., D. Bailbe, and B. Porta. 1989. In vivo insulin resistance in streptozotocin-diabetic rats: evidence for reversal following oral vanadate treatment. Diabetologia. 32:185-190.

37. Challis, R. A. J., B. Leighton, F. J. Lozeman, L. Budohoski, and E. A. Newsholme. 1987. Effects of chronic administration of vanadate to the rat on the sensitivity of glycolysis and glycogen synthesis in skeletal muscle to insulin. Biochem. Pharmacol. 36:357-361.

38. Tamura, S., T. A. Brown, R. E. Dubler, and J. Larner. 1983. Insulin-like effects of vanadate on adipocyte glycogen synthase and on phosphorylation of 95,000 dalton subunit of insulin receptor. Biochem. Biophys. Res. Commun. 113:80-86.

39. Tamura, S., T. A. Brown, J. H. Whiple, Y. Fujita-Yamaguchi, R. E. Dubler, and J. Larner. 1984. A novel mechanism for the insulin-like effect of vanadate on glycogen synthase in rat adipocytes. J. Biol. Chem. 259:6650-6658.

40. Gomez-Foix, A. M., J. E. Rodriguez-Gil, C. Fillat, J. J. Guinovart, and F. Bosch. 1988. Vanadate raises fructose 2,6-bisphosphate concentrations and activates glycolysis in rat hepatocytes. Biochem. J. 255:507-512.

41. Shechter, Y., and S. J. D. Karlish. 1980. Insulin-like stimulation of glucose oxidation in rat adipocytes by vanadil (IV) ions. Nature (Lond.). 284:556-558.

42. Bosch, F., J. Ariño, A. M. Gómez-Foix, and J. J. Guinovart. 1987. Glycogenolytic, noninsulin-like effects of vanadate on rat hepatocyte glycogen synthase and phosphorylase. Biochem. J. 262:218-222.

43. Rodriguez-Gil, J. E., A. M. Gomez-Foix, C. Fillat, F. Bosch, and J. J. Guinovart. 1991. Activation by vanadate of glycolysis in hepatocytes from diabetic rats. Diabetes. 40:1355-1359.

44. Clark, A. S., J. M. Fagan, and W. E. Mitch. 1985. Selectivity of the insulinlike actions of vanadate on glucose and protein metabolism in skeletal muscle. Biochem. J. 232:273-276.

45. Bosch, F., M. Hatzoglou, E. Park, and R. W. Hanson. 1990. Vanadate inhibits expression of the gene for phosphoenolpyruvate carboxykinase (GTP) in rat hepatoma cells. J. Biol. Chem. 265:13677-13682.

46. Miralpeix, M., J. F. Decaux, A. Kahn, and R. Bartrons. 1991. Vanadate induction of L-type pyruvate kinase mRNA in adult rat hepatocytes in primary culture. Diabetes. 40:462-464.

47. Wynshaw-Boris, A., T. G. Lugo, J. M. Short, R. E. K. Fournier, and R. W. Hanson. 1984. Identification of a cAMP regulatory region in the gene for rat cytosolic phosphoenolpyruvate carboxykinase (GTP): use of chimeric genes transfected into hepatoma cells. J. Biol. Chem. 259:12161-12169.

48. Wynshaw-Boris, A., J. M. Short, D. S. Loose, and R. W. Hanson. 1986 Characterization of the phosphoenolpyruvate carboxykinase (GTP)promoterregulatory region. I: Multiple hormone regulatory elements and the effects of enhancers. J. Biol. Chem. 261:9714-9720.

49. Short, J. M., A. Wynshaw-Boris, H. P. Short, and R. W. Hanson. 1986 Characterization of the phosphoenolpyruvate carboxykinase (GTP) promoterregulatory region. II: Identification of cAMP and glucocorticoid regulatory domains. J. Biol. Chem. 261:9721-9726.

50. Peterson, D. D., M. A. Magnuson, and D. K. Granner. 1988. Location and characterization of two widely separated glucocorticoid response elements in the phosphoenolpyruvate carboxykinase gene. Mol. Cell. Biol. 8:96-104.

51. Quinn, P. G., T. W. Wong, M. A. Magnuson, J. B. Shabb, and D. K. Granner. 1988. Identification of basal and cyclic AMP regulatory elements in the promoter of the P-enolpyruvate carboxykinase gene. Mol. Cell. Biol. 8:34673475 .
52. Park, E. A., W. J. Roesler, J.-S. Liu, D. J. Klemm, A. Gurney, J. D. Thatcher, J. Shuman, A. Friedman, and R. W. Hanson. 1990. The role of the CCAAT/enhancer-binding protein in the transcriptional regulation of the gene for phosphoenolpyruvate carboxykinase (GTP). Mol. Cell. Biol. 10:6264-6272.

53. Hatzoglou, M., E. Park, A. Wynshaw-Boris, H.-L. Cheng-Kaung, and R. W. Hanson. 1988. Hormonal regulation of chimeric genes containing the phosphoenolpyruvate carboxykinase promoter regulatory region in hepatoma cells infected by murine retroviruses. J. Biol. Chem. 263:17798-17808.

54. McKnight, S. L., M. D. Lane, and S. Gluescksohn-Waelsch. 1989. Is CCAAT/enhancer-binding protein a central regulator of energy metabolism? Genes Dev. 3:2021-2023.

55. Friedman, A. D., W. H. Landschulz, and S. L. McKnight. 1989. CCAAT/ enhancer binding protein activates the promoter for the serum albumin gene in cultured hepatoma cells. Genes Dev. 3:1314-1322.

56. Feliu, J. E., L. Hue, and H.-G. Hers. 1977. Regulation "in vitro" and "in vivo" of adenosine 3':5'-monophosphate-dependent inactivation of rat liver pyruvate kinase type-L. Eur. J. Biochem. 81:609-617.

57. Davidson, A. L., and W. J. Arion. 1987. Factors underlying significant underestimations of glucokinase activity in crude liver extracts: physiological implications of higher cellular activity. Arch. Biochem. Biophys. 253:156-176.

58. Chirgwin, J. M., A. W. Przybyla, R. J. Mc Donald, and W. J. Rutter. 1979. Isolation of biologically active ribonucleic acid from sources enriched in ribonuclease. Biochemistry. 18:5294-5299.

59. Sokal, R. R., and F. J. Rohlf. 1969. Biometry. The Principles and Practice of Statistics in Biological Research. Freeman, San Francisco. 776 pp.

60. Jantzen, H. M., U. Strähle, B. Gloss, F. Steward, W. Schmid, M. Boshart, R. Moksicek, and G. Schütz. 1987. Cooperativity of glucocorticoid response elements located far upstream of the tyrosine aminotransferase gene. Cell. 49:29-38.

61. Hashimoto, S., W. Schmid, and G. Schütz. 1984. Transcriptional activation of the rat liver tyrosine aminotransferase gene by cAMP. Proc. Natl. Acad. Sci. USA. 81:6637-6641.

62. Schmid, E., W. Schmid, D. Mayer, B. Jastorff, and G. Schütz. 1987. Transcriptional activation of the tyrosine aminotransferase gene by glucocorticoids and cAMP in primary hepatocytes. Eur. J. Biochem. 165:499-506.

63. Lee, K. L., K. R. Isham, A. Johnson, and F. T. Kenney. 1986. Insulin enhances transcription of the tyrosine aminotransferase gene in rat liver. Arch. Biochem. Biophys. 248:597-603.

64. Crettaz, M., D. Muller-Wieland, and C. R. Kahn. 1988. Transcriptional and post-transcriptional regulation of tyrosine aminotransferase by insulin in rat hepatoma cells. Biochemistry. 27:495-500.

65. Pessin, J. E., and G. I. Bell. 1992. Mammalian facilitative glucose transporter family: structure and molecular regulation. Annu. Rev. Physiol. 54:911930.

66. Oka, Y., T. Assano, Y. Shibasaki, J.-L. Lin, K. Tsukuda, Y. Akanuma, and F. Takaku. 1990. Increased liver glucose-transporter protein and mRNA in streptozotocin-induced diabetic rats. Diabetes. 39:441-446.

67. O'Brien, R. M., P. C. Lucas, C. D. Forest, M. A. Magnuson, and D. K. Granner. 1990. Identification of a sequence in the phosphoenolpyruvate carboxykinase gene that mediates a negative effect of insulin on transcription. Science (Wash. DC). 249:533-537.

68. Cimbala, M. A., W. H. Lamers, K. Nelson, J. E. Monahan, H. YooWarren, and R. W. Hanson. 1982. Rapid changes in the concentration of phosphoenolpyruvate carboxykinase mRNA in rat liver and kidney. J. Biol. Chem. 257:7629-7636.

69. Decaux, J. F., D. Robin, P. Robin, and J. Girard. 1988. Intramitochondrial factors controlling hepatic fatty acid oxidation at weaning in the rat. FEBS (Fed. Eur. Biochem. Soc.) Lett. 232:156-158.

70. Quant, P. A., M. P. K. Tubbs, and M. D. Brand. 1987. 3-Hydroxy-3-methylglutaryl coenzyme A synthase activity in rat liver increases with increased ketogenesis. Biochem. Soc. Trans. 15:1068-1069.

71. Christen, P., and P. E. Metzler. 1985. Transaminases. John Wiley \& Sons, Inc., New York.

72. Greengard, O. 1970. The developmental formation of enzymes in rat liver. In Mechanisms of Hormone Action. G. Litwacked, editor. Academic Press, New York. 53-85.

73. Asano, T., H. Katagiri, K. Tsukuda, J.-L. Lin, H. Ishihara, Y. Yazaki, and Y. Oka. 1992. Upregulation of GLUT-2 mRNA by glucose, mannose, and fructose in isolated hepatocytes. Diabetes. 41:22-25.

74. Birkenmeier, E. H., B. Gwynn, S. Howard, J. Jerry, J. L. Gordan, W. H. Landschultz, and S. L. McKnight. 1989. Tissue-specific expression, developmental regulation and genetic mapping of the gene encoding CCAAT/enhancer binding protein. Genes Dev. 3:1146-1156.

75. Ballard, F. J., and R. W. Hanson. 1967. P-enolpyruvate carboxykinase and piruvate carboxylase in developing rat liver. Biochem. J. 104:866-871.

76. Ruppert, S., M. Boshart, F. X. Bosch, W. Schmid, K. R. E. Fournier, and G. Schütz. 1990. Two genetically defined trans-acting loci coordinately regulate overlapping sets of liver-specific genes. Cell. 61:895-904. 